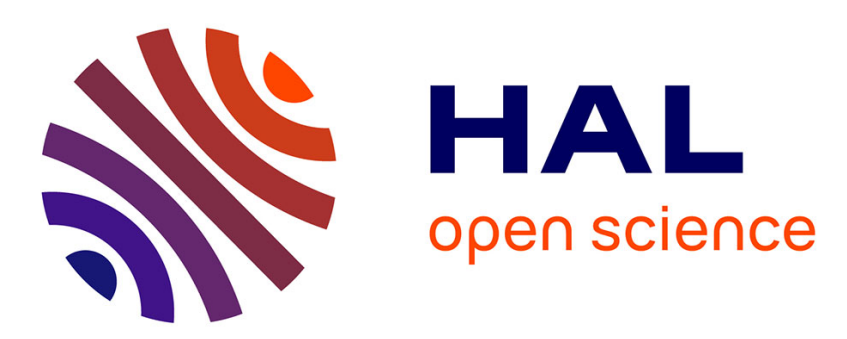

\title{
Experiment and analysis of the effect of BCB sealing ring flatness on BCB cap transfer packaging
}

Seonho Seok

\section{To cite this version:}

Seonho Seok. Experiment and analysis of the effect of BCB sealing ring flatness on BCB cap transfer packaging. Microsystem Technologies, 2020, 10.1007/s00542-020-04945-z . hal-02995284

\section{HAL Id: hal-02995284 \\ https://hal.science/hal-02995284}

Submitted on 9 Nov 2020

HAL is a multi-disciplinary open access archive for the deposit and dissemination of scientific research documents, whether they are published or not. The documents may come from teaching and research institutions in France or abroad, or from public or private research centers.
L'archive ouverte pluridisciplinaire HAL, est destinée au dépôt et à la diffusion de documents scientifiques de niveau recherche, publiés ou non, émanant des établissements d'enseignement et de recherche français ou étrangers, des laboratoires publics ou privés. 


\title{
Experiment and Analysis of the Effect of BCB Sealing Ring Flatness on BCB Cap Transfer Packaging
}

\author{
Seonho Seok \\ C2N/CNRS-University Paris-Saclay, Palaiseau, France \\ e-mail: seonho.seok@c2n.upsaclay.fr
}

\begin{abstract}
This paper presents the effect of BCB sealing ring flatness on BCB bonding for wafer-scale BCB cap transfer packaging. BCB sealing ring has shown partial bonding or full bonding depending on its flatness. It is found that the principal cause of the partial bonding is due to non-flat $\mathrm{BCB}$ sealing ring caused by multilayer BCB coating process. As a solution, BCB dry etching has been proposed to improve the flatness of the BCB sealing ring for full BCB bonding. Besides, partial bonding of $\mathrm{BCB}$ ring has been analyzed through FEM modeling of $B C B$ cap with a non-flat sealing ring. The FEM model consists of $\mathrm{Si}$ carrier wafer, $\mathrm{BCB}$ cap, and $\mathrm{Si}$ target substrate. Unique load is applying pressure on top of Si carrier wafer like wafer-scale bonding. The role of applying pressure is to get $\mathrm{BCB}$ sealing ring to be contacted and expand bondable area with target $\mathrm{Si}$ substrate. As $\mathrm{BCB}$ sealing ring is bonded through $B C B$ polymerization by holding the pressure for 1 hour at $250{ }^{\circ} \mathrm{C}$, mechanical properties of virgin $\mathrm{BCB}$ sealing ring has been changed during bonding. Thus, it has been chosen as variable for parametric analysis. Also, BCB cap dimension has been used as another parameter for the parametric analysis.
\end{abstract} FEM.

Keywords-Flatness, BCB sealing ring, packaging, polymer,

\section{INTRODUCTION}

Polymer materials have been widely used as an intermediate layer or encapsulation caps in MEMS packaging $[1,2]$. The polymer intermediate materials are used as sealing ring between packaging caps and device substrate since most of the packaging caps are glass or $\mathrm{Si}$. They are bonded by means of thermocompression bonding or laser. Low temperature bonding capability of the polymer is particularly attractive as high process temperature in MEMS packaging could create thermal mechanical failure of MEMS devices. For usage, polymer material with high viscosity is dispensed in a cap wafer with a housing cavity for MEMS device. Due to the high topography of the MEMS packaging cap, wafer-scale coating of the polymer on MEMS cap wafer could create non-flat sealing ring on the rim of packaging cap [3]. Such a non-flat polymer ring can be a reason of low bonding strength of MEMS package [4]. Thus, novel fabrication methods have been reported to implement the flat polymer ring on MEMS packaging cap with housing cavities [4]. Recently, polymer cap encapsulation has been presented to take advantages of lowprofile and low packaging loss for high frequency devices [5, 6]. The polymer cap packaging of MEMS devices has been realized in two different ways; 1) release of packaging cap 2) transfer of packaging cap. Polymer cap release has been carried out by plasma etch of organic sacrificial layer through access holes or wet etch of the polymer cap partially cross-linked. Transfer packaging of polymer cap needs a temporary carrier wafer to literally transfer the fabricated packaging cap to a target device substrate. When the polymer packaging cap is prepared in a carrier wafer, we ought to use multilayer coating of the polymer to build packaging cover and the sealing ring of the packaging cap. When polymer sealing ring is coated on pre-patterned polymer cover, sealing ring layer shows certain non-flatness due to surface profile of the pre-patterned polymer cover layer. Moreover, polymer sealing ring is directly affected by the non-flatness since it should be built in the rim of polymer cover. It is thought that non-flat polymer sealing ring would not be significant because high applying bonding pressure can flatten it resulting in expansion of bonding area. Therefore, it is necessary to study the effect of non-flat polymer ring on polymer cap transfer packaging. FE (Finite Element) model is useful technique to evaluate mechanical stress and deformation of a MEMS package [7] and to investigate contact surface behavior when two different materials are jointed or contacted [8].

In this paper, experimental results effect of flatness of $\mathrm{BCB}$ sealing ring on $\mathrm{BCB}$ packaging cap bonding and corresponding FEM analysis have been presented. BCB cap transfer packaging and experimental results of $\mathrm{BCB}$ cap transfer packaging with two different $\mathrm{BCB}$ sealing ring flatness are presented in Section II. FEM modeling and simulation of $\mathrm{BCB}$ cap packaging with non-flat $\mathrm{BCB}$ ring explained in Section III. Finally, conclusion will be made in Section IV.

\section{BCB CAP TRANSFER PACKAGING AND BCB SEALING RING NONFLATNESS}

Fig. 1 shows BCB cap transfer packaging process based on photosensitive $\mathrm{BCB}$ multilayer coating [9]. As shown in Fig. 1, BCB cap is prepared by using spin-coating of photosensitive $\mathrm{BCB}$. BCB cap has one cover layer having thickness of $15-20 \mu \mathrm{m}$ and one sealing ring of $15-20 \mu \mathrm{m}$. The BCB sealing ring can have non-flat shape as it is coated and patterned on the pre-defined $\mathrm{BCB}$ cover and thus it could cause partial bonding of the sealing ring to target $\mathrm{Si}$ substrate. Fig. 2 shows the profile measurement of $\mathrm{BCB}$ sealing ring built on bare silicon wafer and $\mathrm{BCB}$ sealing ring 
on pre-defined $\mathrm{BCB}$ cover respectively. As clearly seen in this figure, flat $\mathrm{BCB}$ ring area is substantially reduced due to pre-patterned $\mathrm{BCB}$ cover.

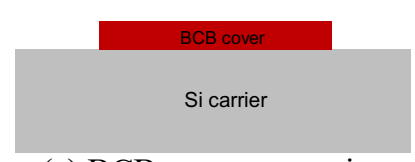

(a) BCB cover patterning

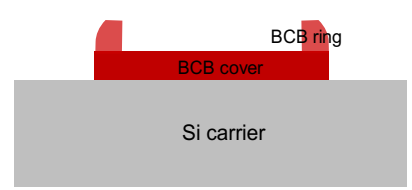

(c) $\mathrm{BCB}$ ring patterning

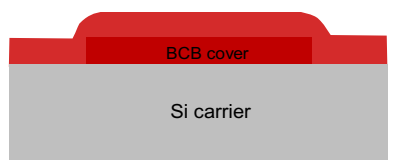

(b) BCB ring coating

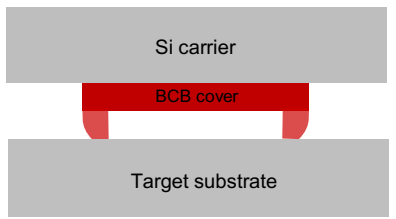

(d) BCB ring bonding
Fig. 1 BCB cap transfer packaging process

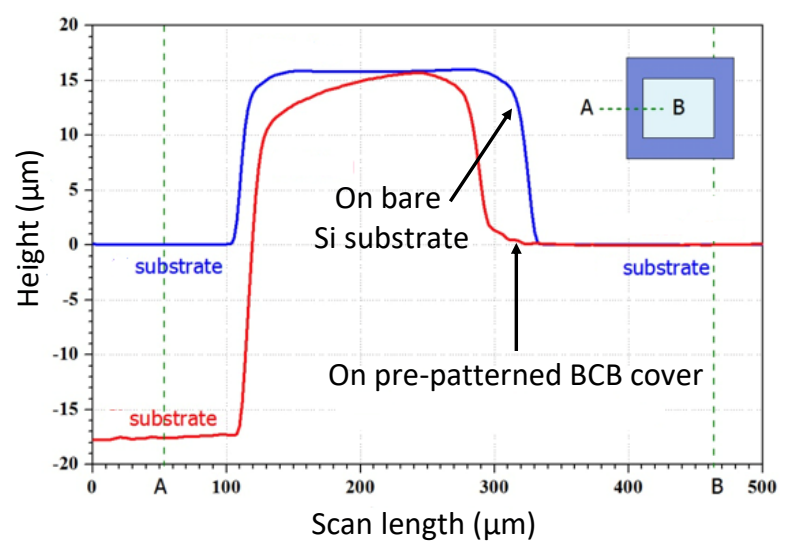

Fig. 2 BCB ring profile on different underlying layers

As the non-flatness of $\mathrm{BCB}$ ring is caused by coating on a pre-defined $\mathrm{BCB}$ layer, dry etch-based $\mathrm{BCB}$ cap process has been presented as shown in Fig. 3. The difference with the previous one is that $\mathrm{BCB}$ cover layer is not patterned before $\mathrm{BCB}$ ring layer coating. $\mathrm{BCB}$ ring and $\mathrm{BCB}$ cover are defined by using $\mathrm{BCB}$ dry etch to achieve better $\mathrm{BCB}$ sealing ring flatness. BCB cap profile measurement, shown in Fig. 4, validated $\mathrm{BCB}$ ring flatness better than the previous one. Note that outer wall of the BCB sealing still has slightly inclined as it has been defined by wet etch of BCB after photolithography.

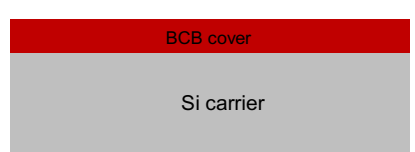

(a) BCB cover coating

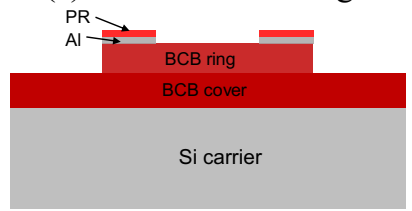

(c) Dry etch mask patterning

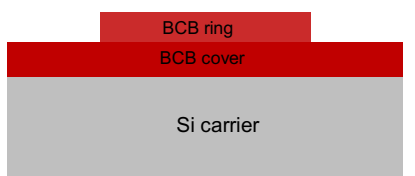

(b) $\mathrm{BCB}$ ring patterning

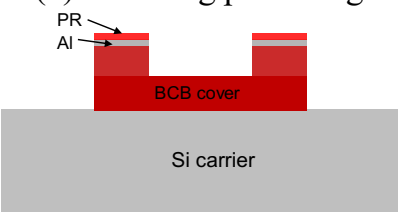

(d) BCB dry etch
Fig. 3 Dry etch-based BCB cap process

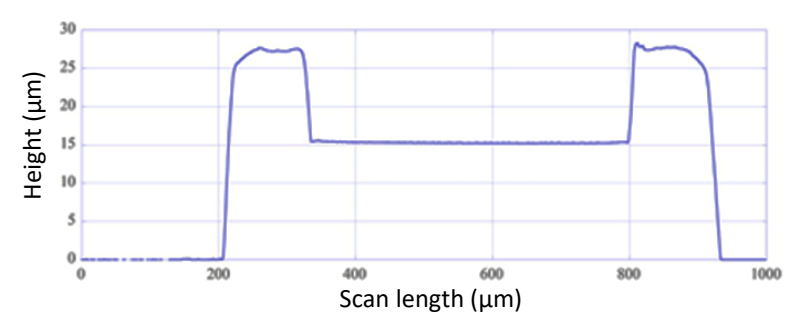

Fig. 4 BCB ring profile after dry etch-based BCB cap process

Wet-etched BCB cap and dry-etched BCB cap are bonded with target substrates in same bonding conditions. The transferred BCB caps are shown in Fig. 5. Wet-etched BCB caps have frequently produced partial bonding due to the non-flat $\mathrm{BCB}$ sealing ring even if large applied pressure, while dry-etched $\mathrm{BCB}$ caps has achieved full bonding. It should be noted that dry-etching process needs high cost due to increased photomasks and process steps.

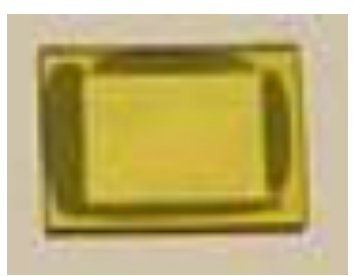

(a) wet-etched BCB cap

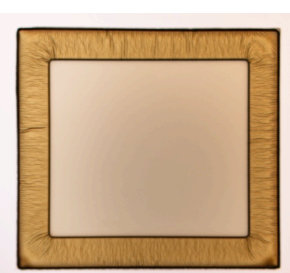

(b) dry-etched BCB cap Fig. 5 BCB cap transfer packaging results 


\section{FEM MODELING AND SIMULATION}

As mentioned in previous section, non-flat BCB sealing have caused partial bonding even if the applied larger bonding pressure. Thus, it is required to study the effect of applying pressure on non-flat $\mathrm{BCB}$ ring at wafer-level bonding. A FEM model of the BCB cap transfer packaging with non-flat BCB sealing ring has been built as shown in Fig. 6. It consists of Si carrier, BCB cap and target $\mathrm{Si}$ substrate as is in the packaging process. Note that it is a quarter model of a single package to reduce element number as well as simulation time. By consequence, boundary conditions are applied as follow; $\mathrm{U}_{\mathrm{x}}=0$ at $\mathrm{x}_{\mathrm{g}}=0, \mathrm{U}_{\mathrm{y}}=0$ at $\mathrm{yg}_{\mathrm{g}}=0$. Bottom surface of $\mathrm{Si}$ substrate is fixed. Si carrier wafer movement are constrained to be in $\mathrm{z}$-axis when bonding pressure is applied on top of Si carrier. Applied force is $1500 \mathrm{~N}$ as is in the experiment [10]. Dimension of each component and material properties are summarized in Table 1 and Table 2 respectively.

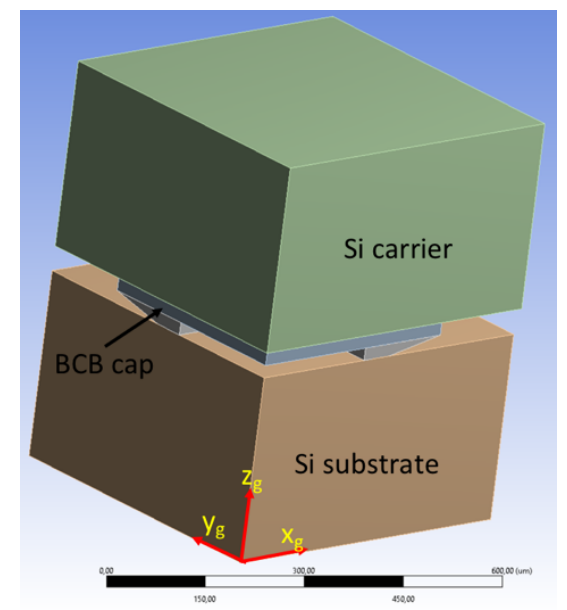

(a) Total model

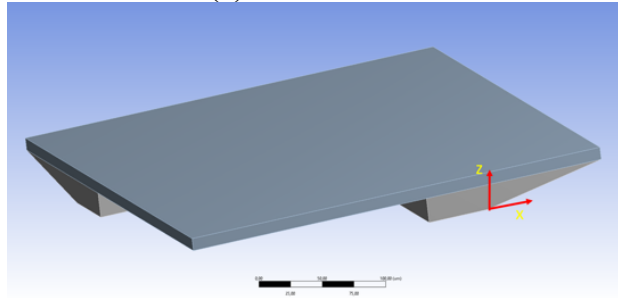

(b) BCB cap

Fig. 6 FEM model of BCB cap transfer packaging with non-flat $\mathrm{BCB}$ sealing ring

Table 1. Dimension of the model

\begin{tabular}{|c|c|c|c|}
\hline & $\begin{array}{c}\text { Length } \\
(\mu \mathrm{m})\end{array}$ & $\begin{array}{c}\text { Width } \\
(\mu \mathrm{m})\end{array}$ & $\begin{array}{c}\text { Thickness } \\
(\mu \mathrm{m})\end{array}$ \\
\hline Si carrier & 500 & 500 & 300 \\
\hline BCB cap & \multicolumn{3}{|l}{} \\
\hline BCB cover & 350 & 350 & 20 \\
\hline BCB ring & 350 & 150 & 20 \\
\hline Si substrate & 500 & 500 & 300 \\
\hline
\end{tabular}

Table 2. Material properties

\begin{tabular}{|c|c|c|}
\hline & Young's Modulus & $\begin{array}{c}\text { Poisson } \\
\text { ratio }\end{array}$ \\
\hline Silicon & $190 \mathrm{GPa}$ & 0.21 \\
\hline $\mathrm{BCB}$ & $3 \mathrm{GPa}$ & 0.34 \\
\hline
\end{tabular}

To reflect the non-flat $\mathrm{BCB}$ ring, it is modelled as two different parts as depicted in Fig. 7; bonded and non-bonded. As non-flat BCB ring has been bonded from inner part of the ring to outer side, it is modelled to have bonded contact and frictional (non-bonded) contact. The bonded contact of the $\mathrm{BCB}$ cap means $\mathrm{BCB}$ cap has good bonding, while the frictional one is used to monitor the behavior of $\mathrm{BCB}$ cap deformation due to applied bonding pressure. The bonded contact has $50 \mu \mathrm{m}$ width and the remained area of the $\mathrm{BCB}$ sealing ring are defined as frictionless one. As the $\mathrm{BCB}$ ring has $150 \mu \mathrm{m}$, the unbonded ring width is $100 \mu \mathrm{m}$.

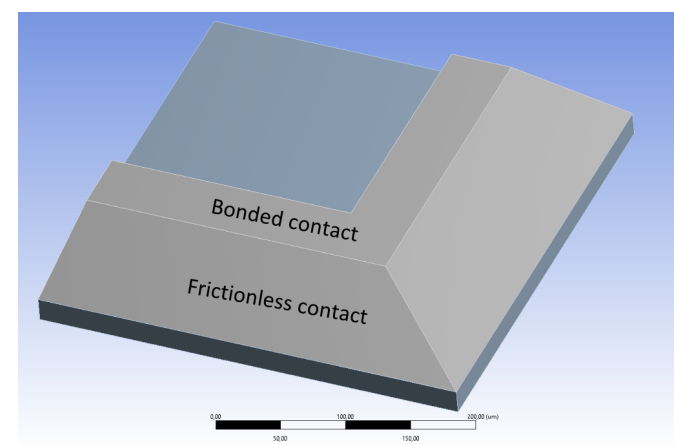

Fig. 7 Contact surfaces of BCB cap

Displacement in z-axis direction and corresponding stress are shown in Fig. 8. BCB cap associated with bonded BCB ring has slightly smaller displacement than other parts of the $\mathrm{BCB}$ cap and thus maximum stress is found inner side of $B C B$ ring. The maximal stress of $\mathrm{BCB}$ cap is much lower than yield stress of $\mathrm{BCB}$ polymer of $87 \pm 9 \mathrm{MPa}$ [9]. Fig. 8 (c) shows deformed $\mathrm{BCB}$ ring along the slope of the unbonded $\mathrm{BCB}$ ring referring to $\mathrm{x}$ and $\mathrm{z}$ axes as indicated in Fig. 6 . Point crossing with interface between $\mathrm{Si}$ substrate and $\mathrm{BCB}$ ring is upper limit of bonded sealing ring. In this case, the bonded zone is up to $62.5 \mu \mathrm{m}$ among initial unbonded zone of $100 \mu \mathrm{m}$. Applying force of $1500 \mathrm{~N}$ makes total bonded area to be increased by $62.5 \%$ of the unbonded BCB area.

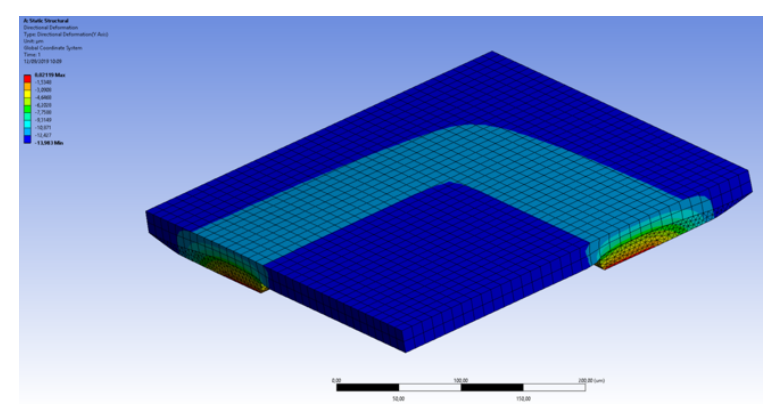

(a) Displacement in Z-axis 


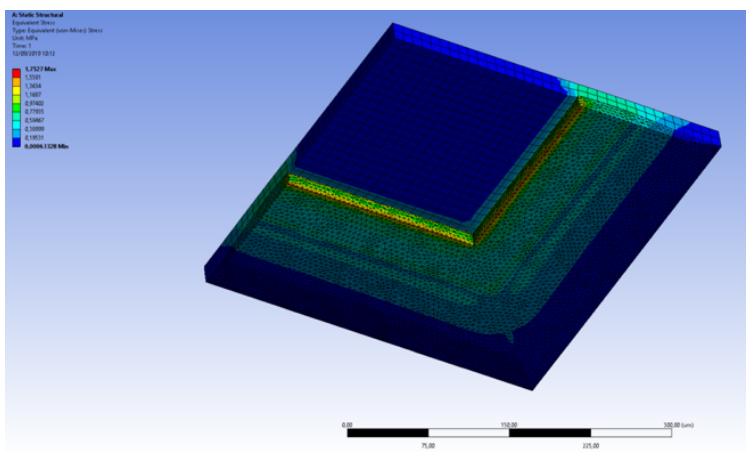

(b) BCB cap stress

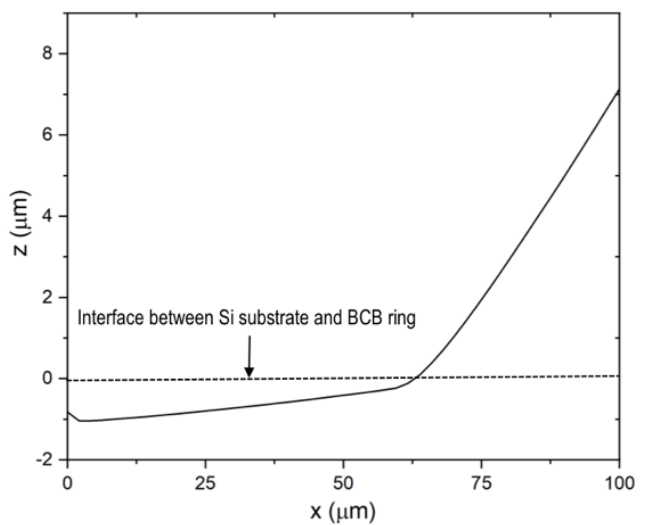

(c)

Fig. 8 FEM simulation results

$\mathrm{BCB}$ ring is assumed to be fully cured in the previous simulation, but it should be partially cured or virgin $\mathrm{BCB}$ ring to achieve good bonding with target Si substrate. During bonding process, force is applied to wafer stack through 3 mm-thick glass pressure diffuser from $150^{\circ} \mathrm{C}$ as seen in Fig. 9. After 10 minutes, temperature goes up to $250^{\circ} \mathrm{C}$ and stays for 1 hour to get the $\mathrm{BCB}$ ring fully-cured. Therefore, a parametric study depending on $\mathrm{BCB}$ ring material properties such as Young's modulus (E) and poisson ratio is required.

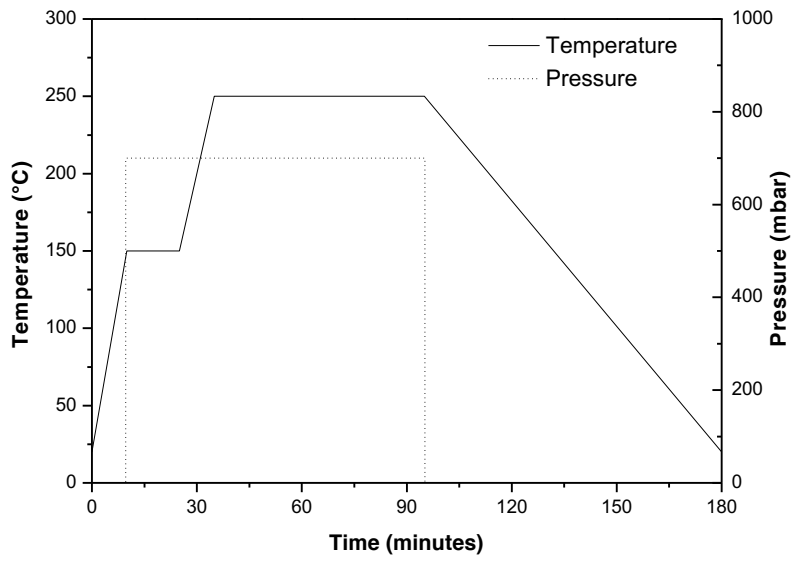

Fig. 9 BCB cap bonding process conditions
At first, Young's modulus of $\mathrm{BCB}$ ring has been changed from $1 \mathrm{MPa}$ to $3 \mathrm{MPa}$ at the step of $1 \mathrm{MPa}$. The increase rate of bonded area is estimated $88 \%$ for $1 \mathrm{MPa}, 70 \%$ for 2 $\mathrm{MPa}$, and $63 \%$ for $3 \mathrm{MPa}$ respectively. Poisson ratio of $\mathrm{BCB}$ ring has values of $0.34,0.40$, and 0.45 makes increase rate to be $63 \%, 61 \%$, and $56 \%$ respectively. Larger poisson ratio is not positive to get large bonding area, which is due to its negative factor into transversal direction. Thus, smaller Young's modulus and smaller poisson ratio are better to get larger bonding area. For BCB ring, it is recommended that it is better to cure it with polymerization rate less than $75 \%$ because it has around $2 \mathrm{MPa}$ of Евсв when it has more than $80 \%$ polymerization rate [11].

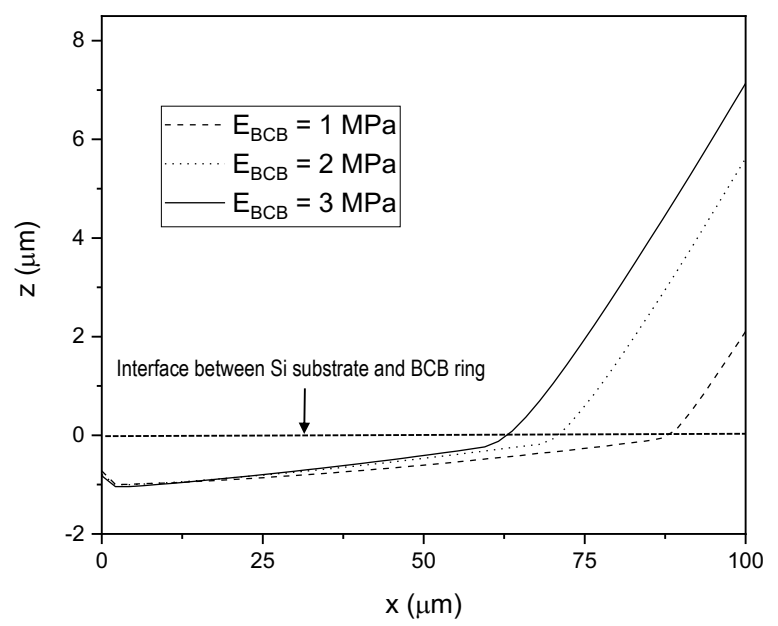

(a) Young's modulus

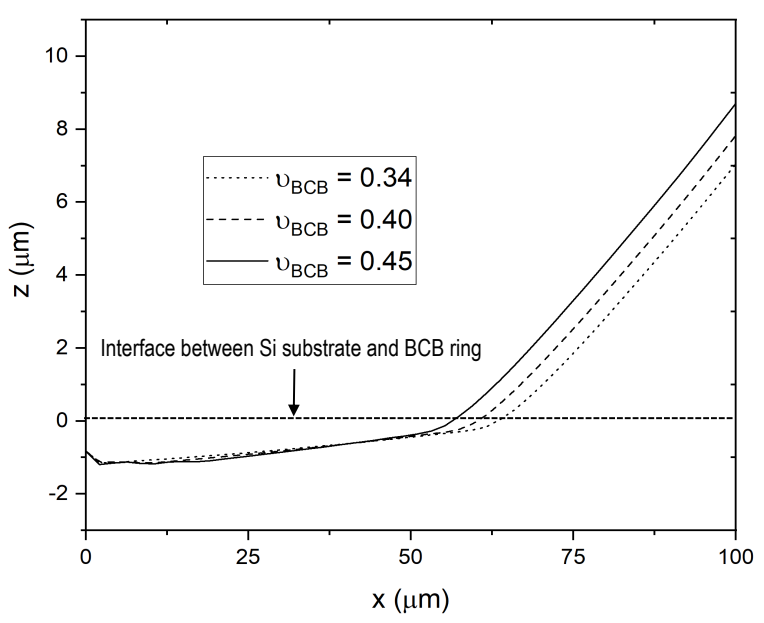

(b) Poisson ratio

Fig. 10 Effect of $\mathrm{BCB}$ ring material properties

The effect of BCB layer thickness is also studied as the geometical design can be a way to compensate non-flat $\mathrm{BCB}$ ring. $\mathrm{As} \mathrm{BCB}$ cover thickness increases, bonded area of $\mathrm{BCB}$ ring is also increased. $\mathrm{BCB}$ ring thickness makes same tendency as the $\mathrm{BCB}$ cover thickness. It would be 
effect of length of BCB layer which means longer one makes larger deformation at same applied load when strain of the material is maintained. Note that $\mathrm{BCB}$ ring nonflatness defined in Fig. 6 (b) has been applied for all the $\mathrm{BCB}$ ring thickness and thicker $\mathrm{BCB}$ layer has demerits in view of mechanical stress and process cost.

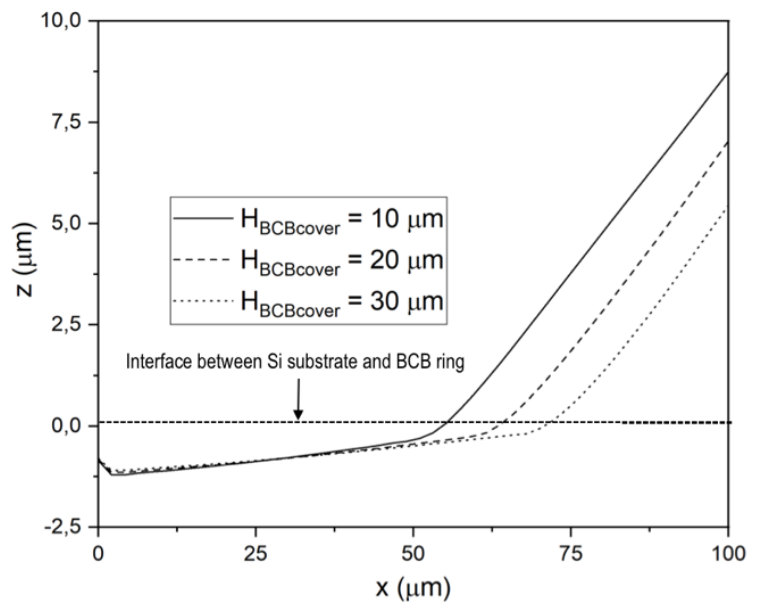

(a) BCB cover thickness

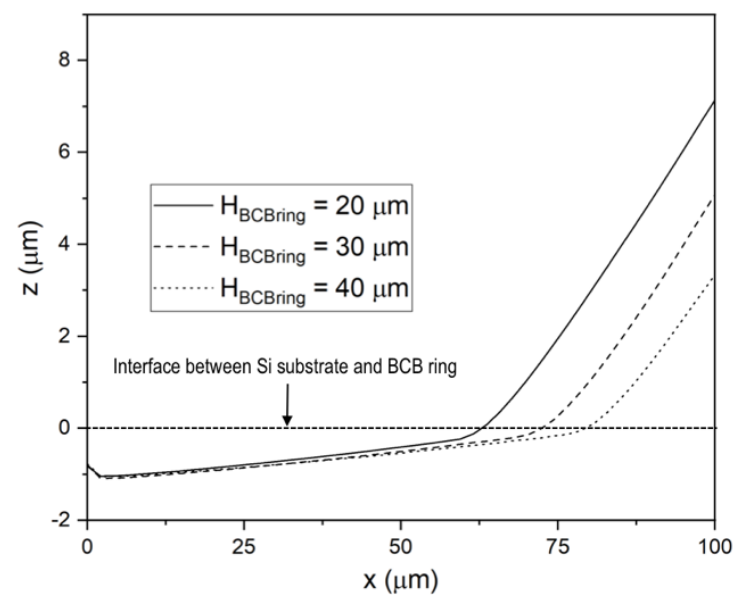

(b) BCB ring thickness

Fig. 11 Effect of BCB cap geometries

\section{CONCLUSIONS}

$\mathrm{BCB}$ ring flatness plays an important role to achieve uniformly sealed ring packaging, which is experimentally proved. Typical photosensitive $\mathrm{BCB}$ polymer creates nonuniform morphology due to multilayer coating on prepattern underlayer. $\mathrm{BCB}$ ring patterned with dry etching is an effective solution to avoid partial bonding of $\mathrm{BCB}$ sealing ring. Through FEM modeling, it is found that Young's modulus of BCB polymer influences much more than poisson ratio, which lead to propose that cure rate of BCB less than $75 \%$ would be an alternative way to improve $\mathrm{BCB}$ ring bonding. Besides, geometrical parameters such as thickness of $\mathrm{BCB}$ cap have been studied and found to be effective for the issues related with $\mathrm{BCB}$ ring flatness.

\section{REFERENCES}

[1] Flavio GiacomozziEmail authorViviana MulloniSabrina ColpoAlessandro FaesGuido SordoStefano Girardi, "RF-MEMS packaging by using quartz caps and epoxy polymers", Microsystem Technologies, Volume 21, Issue 9, September 2015, pp 1941-1948.

[2] C. H. Wang, et al, "Chip scale studies of BCB based polymer bonding for MEMS packaging", 58th Electronic Components and Technology Conference, 2008.

[3] Z. Gong, et al, "Wafer-Level Packaging Method for RF MEMS Applications Using Pre-Patterned BCB Polymer", Micromachines 2018, 9, 93; doi:10.3390/mi9030093.

[4] Seonho Seok, Michel Fryziel, Nathalie Rolland and Paul-Alain Rolland, "Enhancement of Bonding Strength of Packaging Based on BCB Bonding for RF Devices", Microsystem Technologies, Volume 18, Issue 12 (2012), Page 2035-2039.

[5] S. Seok, N. Rolland and P. -A. Rolland, "Packaging methodology for RF devices using a BCB membrane transfer technique", Journal of Micromechanics and Microengineering, vol. 16, No. 11, Nov. 2006, pp.2384-2388.

[6] Imed Zine-El-Abidine, and Michal Okoniewski, "A LowTemperature SU-8 Based Wafer-Level Hermetic Packaging for MEMS Devices",IEEE Transactions on Advanced Packaging, Vol. 32, No. 2, May 2009, pp.448-452.

[7] S. Satyajit, et al, "Evaluation of Die Stress in MEMS Packaging: Experimental and Theoretical Approaches", IEEE Transactions on Components and Packaging Technologies, Vol. 29, Issue 4, Dec. 2006, pp. 735-742.

[8] Seonho Seok, "Fabrication and Modeling of Nitride Thin Film Encapsulation Based on Anti-Adhesion-Assisted Transfer Technique and Nitride/BCB Bilayer Wrinkling", IEEE Transaction on Components, Packaging, Manufacturing Technology (CPMT), 2016, Vol.6, No.9, Sept. 2016, pp.1301-1307.

[9] Dow Chemical Company, Processing Procedures for CYCLOTENE 4000 Series Photo BCB Resins, February 2005.

[10] Janggil Kim, Seonho Seok, and Nathalie Rolland, "Polymer-based Zero-Level Packaging Technology for High Frequency RF Applications by Wafer Bonding/Debonding Technique Using an Anti-adhesion Layer", International Journal of Precision Engineering and Manufacturing (IJPEM), October 2012, Volume 13, Issue 10, pp. 1861-1867.

[11] M. Wöhrmann, et al, "Low Temperature Cure of BCB and the Influence on the Mechanical Stress", Electronic Components and Technology Conference (ECTC), 2011, pp.392-400. 